\title{
Involvement of Community Pharmacists in Public Health Services in Asir Region, Saudi Arabia: A Cross-sectional Study
}

\author{
Mona Almanasef ${ }^{1}$, Dalia Almaghaslah² ${ }^{2}$ Geetha Kandasamy $^{1}$, Rajalakshimi Vasudevan ${ }^{3}$, \\ and Sadia Batool ${ }^{1}$ \\ ${ }^{1}$ King Khalid University \\ ${ }^{2}$ King Khalid University College of Science \\ ${ }^{3}$ Affiliation not available
}

July 15, 2021

\begin{abstract}
Background: Community pharmacists are one of the most accessible healthcare practitioners worldwide used by a large proportion of the population. Expanding the roles of community pharmacists could contribute to reducing pressure on general health practice and other areas of the health services. This research aimed to evaluate the contribution of community pharmacists in the provision of public health services and to investigate the perceived barriers for the provision of these services in Saudi Arabia. Materials \& Methods: This study followed a cross-sectional design using an online anonymous self-administered questionnaire. The study took place in Asir region, Saudi Arabia, between September 2019 and February 2020. A convenience sampling strategy was used to select and recruit the study participants. The questionnaire was adapted from previous research and involved three sections: demographics, involvement in public health services, and barriers for practising public health roles. Results: The total number of respondents was 193. The proportion of respondents who reported that they were "very involved" or "involved" in each service was $61.7 \%$ for weight management, $60.6 \%$ for sexual health, $57.5 \%$ for healthy eating, $53.4 \%$ for physical activity promotion, $51.3 \%$ for dental health, $46.1 \%$ for smoking cessation, $39.4 \%$ for screening for diabetes, $35.7 \%$ for screening for hypertension, $31.1 \%$ for alcohol dependence and drug misuse counselling, $30.6 \%$ for screening for dyslipidaemia, and $21.8 \%$ for vaccination and immunisation. Most of the barriers in the current research were rated as having low relevance to the provision of public health services. Conclusion: Findings in the current research suggest that community pharmacists in Asir region have intermediate to minimal engagement in practicing their public health roles. Further research needs to be undertaken to understand the barriers to the provision of public health services and what strategies would be beneficial for enhancing the public health role of community pharmacists in Saudi Arabia.
\end{abstract}

\section{Hosted file}

Main text file.docx available at https://authorea.com/users/425804/articles/530522involvement-of-community-pharmacists-in-public-health-services-in-asir-region-saudiarabia-a-cross-sectional-study 